\title{
Factors Affecting Menstrual Hygiene Management Practice Among School Adolescents in Ambo, Western Ethiopia, 2018: A Cross-Sectional Mixed-Method Study
}

This article was published in the following Dove Press journal:

Risk Management and Healthcare Policy

\section{Seifadin Ahmed Shallo (iD) Wakeshe Willi ${ }^{2}$ Abuzumeran Abubeker ${ }^{3}$ \\ 'Department of Public Health, Division of Reproductive Health and Nutrition, College of Medicine and Health Sciences, Ambo University, Ambo, Ethiopia; ${ }^{2}$ Department of Public Health, Division of Reproductive Health and Nutrition, Ambo University, Ambo, Ethiopia; ${ }^{3}$ Department of Public Health, Division of Epidemiology, Ambo University, Ambo, Ethiopia}

Background: Menstruation is still regarded as something unclean in many parts of Ethiopia. Despite the challenges related to menstrual hygiene management, it has been routinely overlooked in the school setting. The existing evidence on menstrual hygiene management lacks objective measurement approaches. Therefore, the aim of this study was to assess factors affecting menstrual hygiene management practice among school adolescents in Ambo, Western Ethiopia.

Methods: An institutional-based mixed-method cross-sectional study was conducted from 1 to 30 March 2018 with 364 high school females. A systematic random sampling and purposive sampling technique were used to select study participants. We used a self-administered questionnaire, observational checklists, and focus group discussion. Data were analyzed using SPSS statistical software and thematic analysis. Multiple logistic regression analyses were done. With $95 \%$ CI, $\mathrm{P}<0.05$ was considered the level of significance.

Results: The prevalence of unsafe menstrual hygiene management practice was $53.6 \%$, and it was affected by factors including age of the females [AOR: $0.16(0.045,0.57), \mathrm{P}=0.005$ ], frequency of discussing menses [AOR: $0.30,95 \% \mathrm{CI}: 0.13,0.71, \mathrm{P}$-value $=0.006$ ], and source of information about menses [AOR: $3.75,95 \% \mathrm{CI}: 1.75,8.00) \mathrm{P}=0.001$ ]. Lack of information about how to manage menses safely and lack of sufficient WASH facility were also identified.

Conclusion: High prevalence of unsafe menstrual hygiene management in the study area implies that urgent measures are needed from the concerned body. The school environments were not female friendly for managing their menses safely highlighting that the water, sanitation, and hygiene facilities in the schools need urgent solutions.

Keywords: menstrual hygiene management, school females, Ambo, Ethiopia

\section{Background}

Menstrual hygiene management (MHM) is personal hygiene practices during menstruation which starts with the choice of the best sanitary materials, their proper use, disposal, and body cleanliness. ${ }^{1}$ Menstruation is still regarded as something unclean or dirty in some societies. The seclusion of menstruating females and restrictions imposed on them in the family not to participate in a range of activities while on menses have reinforced a negative attitude toward this phenomenon. ${ }^{2,3}$ Worldwide, nearly $52 \%$ of the female populations are of reproductive age. Despite the
Correspondence: Seifadin Ahmed Shallo Department of Public Health, Division of Reproductive Health and Nutrition, College of Medicine and Health Sciences, Ambo University, Ambo, Ethiopia Email Seifadinahmed8226@gmail.com
Risk Management and Healthcare Policy 2020:I3 I579-I587

mit your manuscript (c) (i) (5) 2020 Ahmed Shallo et al. This work is published and licensed by Dove Medical Press Limited. The full terms of this license are available at https://www.dovepress.com/ CY ${ }_{\mathrm{BC}}$ terms.php and incorporate the Creative Commons Attribution - Non Commercial (unported, v3.0) License (http://creativecommons.org/licenses/by-nc/3.0/). By accessing the work you hereby accept the Terms. Non-commercial uses of the work are permitted without any further permission from Dove Medical Press Limited, provided the work is properly attributed. For permission for commercial use of this work, please see paragraphs 4.2 and 5 of our Terms (https://www.dovepress.com/terms.php). 
challenges related to menstrual hygiene management, menstrual hygiene has been routinely ignored by professionals in the education sector. ${ }^{4}$

In Ethiopia, like other African countries, MHM is one of the critical problems adolescent girls face while they are in school. Most schools in the country are not equipped with the basic amenities for menstrual management such as menstruation materials, places for changing menstruation materials, running water, and disposal facilities. A study conducted in the Amhara region, Ethiopia, revealed that only $35 \%$ of the school females used sanitary napkins, while $55 \%$ used homemade materials during their recent menses. ${ }^{5}$ Approximately $11 \%$ of girls change their menstrual clothes once a day. They commonly use rags from old clothes and use their dress tied in a knot to keep the sanitary clothes in place. Most girls rinse their rags in water without using soap, dry them under the bed, and hang them in hidden, often unhealthy places in the house or on the roof. Such practices may increase their susceptibility to infections. ${ }^{1}$ This is mainly due to a lack of infrastructure as well as poor management of the existing facilities. ${ }^{6}$ The commercially available reusable sanitary pads are not affordable for many of the school females because of high cost. In addition, lack of awareness from where to access and how to use the napkins were also some of the reasons reported as factors hindering females not to use a napkin. ${ }^{3}$ The magnitude of unsafe MHM practice among females was $60 \%$ in Nekemte, Oromia regional state, $75.5 \%$ in Bahardar, Amhara regional state, $49.8 \%$ in Addis Ababa, Ethiopia. ${ }^{7,8}$

In Uganda Hennegan et al identified that nearly $90 \%$ of school girls did not meet the minimal criteria for safe MHM. Concomitantly, the rate of genital irritation, discharge, and concern of malodor is higher among poor MHM girls. In addition to missing school, poor MHM also leads to a feeling of shame, worrying that odor may disturb the class, and low self-esteem, which may result in psychological problems like depression during menses. The study conducted in Indonesia also revealed the magnitude of unsafe menstrual hygiene was $64 \%{ }^{9}, 10$

Poor menstrual hygiene and inadequate self-care are major determinants of morbidity and complications among younger females. Some of these problems include reproductive tract infections, urinary tract infections, scabies in the vaginal area, abdominal pain, absence from school, and complications during pregnancy. Baisley et al reported that using cloths or cotton wool for menstrual hygiene is the single most predictive factor for bacterial vaginosis infection. ${ }^{11,12}$

Due to economic constraints or being taboo to ask parents for money to buy sanitary pads, females turn to transactional sex to get money for sanitary pads. ${ }^{13}$ Sex education is also often neglected from the school curriculum. $^{14,15}$

Proper disposal of used menstrual material is still a challenge for many countries of the world. Most females dispose of used sanitary pads or other menstrual articles into household solid waste or garbage bins. ${ }^{16}$

In general, the implementation of safe and effective MHM practice programs will contribute towards the achievement of sustainable development goals (SDG) targets in education, gender equality, reduction of maternal mortality, and water and sanitation.

A comprehensive definition of MHM was developed by the Joint Monitoring Program of the Emory University and UNICEF in 2012, defining MHM as: "Women and adolescent girls using a clean menstrual management material to absorb or collect blood that can be changed in privacy as often as necessary for the duration of the menstruation period, using soap and water for washing the body as required and having access to facilities to dispose of used menstrual management materials". 17

As per the above definition, adequate MHM would require the following main components: clean absorbents; adequate frequency of absorbent change; washing the body with soap and water; adequate disposal, privacy for managing menstruation and appropriate disposal of used absorbents.

However, the prevalence studies conducted so far on MHM practice among school female adolescents in Ethiopia focus only on the type of absorbents used, one aspect of the components of MHM, to classify MHM as good or poor, making it difficult to conclude the actual magnitude of the problem.

Therefore, this study aimed to assess practices of MHM and associated factors among high school females in Ambo city, Ethiopia by applying the UNICEF definition of the safe menstrual hygiene management. Specifically, the following questions were addressed:

1. How many high school females practiced unsafe MHM?

2. What were the underlying determinants of MHM practices among high school females?

\section{Methods}

\section{Study Area}

The study was conducted in Ambo city, Oromia regional state, Ethiopia. Ambo is the capital city of West Shoa 
Zone, located $114 \mathrm{~km}$ from Addis Ababa. As the data from the Ambo City Administrative education office indicates, there are three private colleges, two preparatory schools, five high schools, and seventeen primary schools in the City and Ambo woreda. There are five high schools (4 governmental and 1 private) in Ambo city. The total number of students enrolled in high school levels for the academic year 2017/18 was 5230, of which 2401 were females.

\section{Study Design and Period}

An institutional-based cross-sectional study was conducted, and data were collected during March 1 to 30, 2018.

\section{Inclusion and Exclusion Criteria}

All female students who had started experiencing menses were included. The participants for the quantitative study were randomly selected female students, while participants for the qualitative study were purposively selected female students.

\section{Sample Size Determination and Sampling Procedure}

The sample size was determined based on the assumption of a simple random sampling (SRS) method and using a single population proportion formula. Since we were unable to locate a similar study, we decided to take $\mathrm{P}=50 \%$, assuming that $50 \%$ of school female adolescents were practicing unsafe MHM. With a 0.05 margin of error, the sample size was calculated as follows:

$$
\begin{aligned}
\mathrm{n} & =\frac{(\mathrm{Z} \alpha / 2)^{2} \mathrm{p}(1-\mathrm{p})}{\mathrm{d}^{2}}=\frac{(1.96)^{2} \mathrm{X}(0.50 \times 0.50)}{(0.05)^{2}} \\
& =\frac{0.9604}{0.0025}=384
\end{aligned}
$$

Since the source population was finite $(<10,000)$, the sample size correction formula was applied and a $10 \%$ non-response rate was added. The final sample size was 364. The participants from each school were selected based on the proportion of female students they had. The sample size for the qualitative study (FGD) was determined based on the saturation of ideas. Accordingly, five FGD, one at each school, was conducted among school females.

Five FGD, duration 40-60 minutes each, were conducted to explore female students' experience, challenges, and needs related to MHM. The FGD guide and observational checklists were adopted and contextualized from UNICEF's tools developed to assess MHM in the school setting. ${ }^{18}$ A total of 36 school females participated in FGD. They were selected purposively with the help of the schools' heads. The FGDs were tape-recorded and transcribed later. Data analysis used a thematic approach. Data from all transcripts were placed under the relevant theme where it complemented the quantitative findings.

The school observation was conducted among all the five schools using the standard checklist developed by UNICEF to assess the WASH in the school setting, and contextualized to the local setting. The observers were the investigators themselves. Initially, the investigators come together and discussed the tools i.e. observation checklists, and reached upon common understanding. Three observers were sent to each school. They fill the checklists independently and finally compiled it together. Since the checklist was clear and objectively measurable, no observer difference was reported.

\section{Data Collection Instrument}

Self-administered semi-structured questionnaires were used to collect quantitative data. The questionnaires were adapted from UNICEF's tools developed to assess MHM in the school setting and other related literature. ${ }^{18}$ Five, diploma holding, females were recruited and trained on data collection tools and methods for two days. The questionnaire was first prepared in English and then translated into Afan Oromo and Amharic (the local languages). Observational checklists, which assess the WASH status in the schools, were also used. We used a systematic random sampling technique to select the study participants. The students' identity number was retrieved from each school record offices and used as a sample frame.

\section{Data Quality, Management, and Analysis}

To ensure the quality of the data, first, the questionnaire was pre-tested and data collectors were trained well. A descriptive analysis was computed. Binary logistic regression was done to assess the association between dependent and independent variables. Variables associated with the dependent variable at $p$-value $\leq 0.25$, and the variables that were known to have an association with dependent variables from previous studies were selected for multiple logistic regression analysis. With a $95 \%$ confidence interval (CI), statistical significance was declared at $\mathrm{P}<0.05$.

\section{Analysis of Qualitative Data}

The data collected through FGD and observation was analyzed by open coding with thematic analysis approach. Four themes were separately prepared initially. They are: school females' experience; school females need concerning MHM; awareness about MHM; and their perception 
about WASH facility in their school. The detail is presented in Table 1.

\section{Outcome Variable}

Menstrual hygiene management practices (safe or unsafe)

\section{Measurements}

Safe menstrual hygiene practice was measured based on the UNICEF definition of safe menstrual hygiene containing four criteria i.e. type of absorbents used, frequency of absorbent exchange, frequency of washing genitalia during menses, and disposal methods for used absorbents. ${ }^{17}$ Accordingly, the females' menstrual hygiene practice is safe if it fulfills all of the following four criteria, otherwise, it is considered unsafe: $i$ ) If the females used safe absorbents (considered safe if they were commercially available sanitary pads or new clothes or re-usable type, used after washing with soap); ii) Changing absorbents twice or more times per 24 hours; iii) If girls wash their genitalia twice or more times per 24 hours and iv) disposed of menstruation pad by burying or burn it after use. ${ }^{8,10}$ If the respondents fulfill the criteria on a single criterion, 1 point was given and otherwise, zero was given. Finally, the value was added up together for all four variables (criteria). Those who score four out of four were classified as safe menstrual hygiene practice and otherwise classified as unsafe.

\section{Ethical Approval and Consent to Participate}

This study was conducted in accordance with the Helsinki declaration. The ethical clearance was obtained from the

Table I Themes and Subthemes Extracted from the Focus Group Discussion Conducted Among High School Females in Ambo City, Ethiopia, 2018

\begin{tabular}{|l|l|}
\hline Themes & Subthemes \\
\hline I. Females experience & $\begin{array}{l}\text { Stigma/shame } \\
\text { Fear of sudden blood leakage } \\
\text { School absenteeism } \\
\text { Drown attention in the class }\end{array}$ \\
\hline 2. Need & $\begin{array}{l}\text { Privacy at school } \\
\text { Type of absorbents } \\
\text { Accessibility, availability, and affordability of } \\
\text { absorbents }\end{array}$ \\
\hline 3. Awareness & $\begin{array}{l}\text { Lack of information about menses and } \\
\text { MHM }\end{array}$ \\
\hline $\begin{array}{l}\text { 4. WASH facility in the } \\
\text { school }\end{array}$ & $\begin{array}{l}\text { Lack of water facility at school } \\
\text { Toilet cleanness, presence of door, privacy } \\
\text { Poor Waste disposal }\end{array}$ \\
\hline
\end{tabular}

ethical review board (ERB) of the College of Medicine and Health Sciences, Ambo University, Ethiopia. The letter for support was written from the college of medicine and Health Sciences, Ambo University to all selected Schools.

Before starting the data collection process, the confidentiality of the data to be collected was ensured to the participants, and both written and informed verbal consent was taken from each respondent and their families. In order to ensure the anonymity of the collected data, code number was assigned to the questionnaire, and study participation was entirely voluntary. The informed consent also included publication of anonymized responses.

\section{Availability of Data and Material}

All data generated or analyzed during this study were included in this published article and its supplementary information files are in the hands of the correspondent author and can be accessed on formal requests.

\section{Results}

In this paper, the qualitative finding is grouped under four themes and the detail of the themes is presented in Table 1. The quotes are put under the quantitative findings where it complements each other. The themes were: 1) females' experience about menstruation and MHM, 2) females need, 3) females' awareness towards menses and MHM practice, and 4) females' perception and experience with school WASH facility.

\section{Socio-Demographic Characteristics of the Respondents}

The response rate was $91.6 \%$. The mean age of the participants was 16 (SD 2.25) years. Most participants were urban residents (92.9\%), and single (93.8) (Table 2).

\section{Menstrual Hygiene Management Practice and Knowledge of the School Females}

The mean age at menarche was 13.9 (SD 0.71). Most (about 73\%) reported that they had awareness about menses before menarche. Mothers were the leading (47\%) source of information about menses. Only $31 \%$ reported that they prepared well for the first menses. Of the 336 respondents, $53.6 \%$ (95\% CI: 48.5, 58.6) participants' MHM practices were unsafe. Of the four components, the frequency of washing genitalia during menses was the most poorly managed followed by the disposal of used pads (Table 3). 
Table 2 Socio-Demographic Characteristics of High School Females in Ambo City, 2018

\begin{tabular}{|l|l|l|}
\hline Variables & Frequency & Percent (\%) \\
\hline Age & & \\
$12-17$ & 312 & 92.9 \\
$>18$ & 24 & 7.1 \\
\hline Residence & & \\
Urban & 312 & 92.9 \\
Rural & 24 & 7.1 \\
\hline Marital status (relationship) & & \\
Single & 315 & 93.8 \\
Engaged & 21 & 6.2 \\
\hline Religion & & \\
Orthodox & 158 & 47.0 \\
Protestant & 142 & 42.3 \\
Others* & 36 & 10.7 \\
\hline Mothers educational status & & \\
Illiterate & 66 & 19.6 \\
Grade I-6 & 103 & 30.7 \\
Grade 7-12 & 83 & 24.7 \\
Degree and above & 81 & 24.1 \\
\hline Father's educational status & & 31.8 \\
Illiterate & 59 & 17.6 \\
Grade I-6 & 58 & 111 \\
Grade 7-12 & 107 & \\
Degree and above & & \\
\hline
\end{tabular}

Note: *Wakefata and Muslim.

The respondents were asked: "how you rate your preparedness for the first menses?" with the option of not at all, well prepared, not well prepared or I do not remember. Accordingly, only $31 \%$ reported that they prepared well for the first menses while the others reported not prepared well or do not remember. About 81 (25\%) of the participants do not know the existence of commercially available sanitary pads. Approximately $17 \%$ of the respondents reported that the source of menses blood is organs other than the uterus like the abdomen, vagina, and or other. The respondents were also asked: "what is the cause for the menses bleeding?" and about $26 \%$ reported it is God's curse or disease (Table 4).

The gap in awareness about MHM was also identified during FGD. One of the focus group discussants reported as follows:

.... We have no sufficient information on how to manage menstruation and afraid to ask or discuss the issue of the menstrual cycle, we didn't get any readable material prepared with the local language to get better information and
Table 3 Menstrual Hygiene Management Practice Among High School Females in Ambo City, Ethiopia, 2018

\begin{tabular}{|c|c|c|}
\hline Variables & Frequency & Percent \\
\hline $\begin{array}{l}\text { Do you know the commercially available } \\
\text { sanitary pad } \\
\text { Yes } \\
\text { No }\end{array}$ & $\begin{array}{l}255 \\
81\end{array}$ & $\begin{array}{l}75.1 \\
24.9\end{array}$ \\
\hline $\begin{array}{l}\text { Type of sanitary pad used mostly } \\
\text { Rag (cloth of any kind) } \\
\text { Piece of clean clothes } \\
\text { Disposable sanitary pads } \\
\text { Underwear alone }\end{array}$ & $\begin{array}{l}42 \\
63 \\
218 \\
10\end{array}$ & $\begin{array}{l}12.4 \\
18.6 \\
64.3 \\
2.9\end{array}$ \\
\hline $\begin{array}{l}\text { Frequency of sanitary pad exchange } \\
\text { Once per day } \\
\text { Twice per day } \\
\text { Three times and above }\end{array}$ & $\begin{array}{l}53 \\
245 \\
37\end{array}$ & $\begin{array}{l}15.6 \\
72.3 \\
10.9\end{array}$ \\
\hline $\begin{array}{l}\text { How do you manage menses at school } \\
\text { Used sanitary napkins } \\
\text { Left school } \\
\text { Do nothing }\end{array}$ & $\begin{array}{l}180 \\
111 \\
41\end{array}$ & $\begin{array}{l}53.1 \\
32.7 \\
12.1\end{array}$ \\
\hline $\begin{array}{l}\text { Disposing sanitary pad } \\
\text { In toilet } \\
\text { In dust bin } \\
\text { Open field }\end{array}$ & $\begin{array}{l}228 \\
71 \\
34\end{array}$ & $\begin{array}{l}67.3 \\
20.9 \\
10.1\end{array}$ \\
\hline $\begin{array}{l}\text { How do you clean your body during } \\
\text { menstruation } \\
\text { Take bath with soap } \\
\text { Clean around genitalia with tissue paper } \\
\text { Wash genitalia area with soap }\end{array}$ & $\begin{array}{l}129 \\
56 \\
148\end{array}$ & $\begin{array}{l}38.1 \\
16.5 \\
43.7\end{array}$ \\
\hline $\begin{array}{l}\text { Frequency of cleaning genitalia } \\
\text { Twice a day } \\
\text { Once a day } \\
\text { Do not until the end of menses }\end{array}$ & $\begin{array}{l}70 \\
165 \\
95\end{array}$ & $\begin{array}{l}20.6 \\
48.7 \\
28.0\end{array}$ \\
\hline $\begin{array}{l}\text { Do you usually get pocket money for } \\
\text { sanitary pad } \\
\text { Yes } \\
\text { No }\end{array}$ & $\begin{array}{l}255 \\
81\end{array}$ & $\begin{array}{l}75.9 \\
24.1\end{array}$ \\
\hline $\begin{array}{l}\text { Overall MHM status } \\
\text { Safe* } \\
\text { Unsafe }\end{array}$ & $\begin{array}{l}157 \\
179\end{array}$ & $\begin{array}{l}46.7 \\
53.3\end{array}$ \\
\hline
\end{tabular}

Note: *If it fulfills the four criteria (using safe absorbents, changing absorbents twice/day, washing genital at least twice/day and disposing of the used absorbents in the safe way/or washed with soap, dried on the sun and used it).

knowledge. I, myself feel shame to ask another person about menses. It is taboo in our area to speak about menses ... (Female FGD discussant)

The water, sanitation, and hygiene in the schools were poor. The toilets in the schools lack cleanness, water 
Table 4 Menstrual Hygiene Management Related Knowledge Among High School Females in Ambo City, Ethiopia, 2018

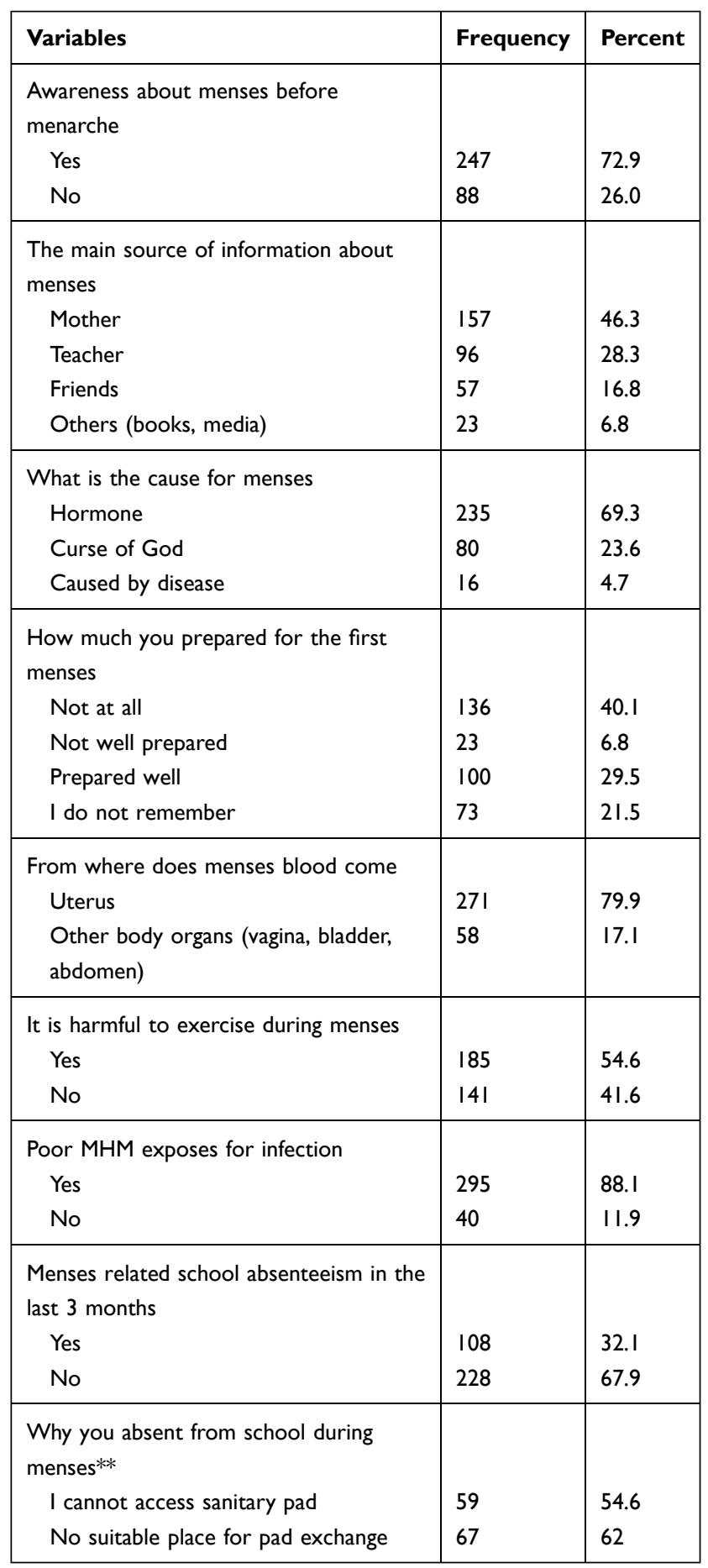

Note: **Since multiple responses are possible, the percent could be greater than $100 \%$.

source, and doors for privacy. As revealed during the FGD, because of the lack of facilities at schools, many females left schools during their menses:

... If I am at home, I change my absorbents twice a day and clean my genitalia, but if I am in the school it is not comfortable because of no water even to wash my hand, the toilets are not clean, lacks a door. It is not comfortable for privacy ... (FGD participant)

.... Usually, I don't come to school during my period eve. If my period comes suddenly while I am at school, my attention becomes drown toward fear of having an accident leakage and I think that if my cloth suddenly stained with leakage of blood, the students may laugh at me. So, I prefer staying at home ... (FGD participants)

\section{Factors Associated with Unsafe Menstrual Hygiene Management}

In multiple logistic regression analyses, variables including: age; religion; father's educational status; and frequency of discussing menses with their mother were significantly associated with the dependent variable. Accordingly, compared with those aged greater or equal to 18 years, females younger than 18 years were $84 \%$ less likely to be their MHM practice was unsafe $95 \% \mathrm{CI}$, [AOR: $0.16(0.045,0.57), \mathrm{P}=0.005]$. Females whose fathers had degree-level education and above were $72 \%$ [AOR: $0.28,95 \%$ CI: 0.10, 0.88, P-value $=0.03$ ] less likely to manage their menses unsafely. Compared with those females who never discussed menses with their mother, females who frequently discussed were $70 \%$, [AOR: $0.30,95 \%$ CI: $0.13,0.71$, P-value $=0.006$ ] less likely to manage their MHM safely (Table 5).

\section{Discussion}

In this study, it is identified that more than half of the females' MHM practice was unsafe. This finding is lower compared with studies conducted in Bahir Dar and Nekemte, Ethiopia, and Uganda. ${ }^{10,16}$ The difference could be due to measurement differences and study place differences. Mothers were the main source of information about menses. A similar finding was reported previously. ${ }^{19,20}$ Of respondents, $64.3 \%$ used a sanitary pad in the current study, and this is higher compared to the previous study conducted in Bahir Dar and Wollo where only $44.9 \%$ and $33 \%$ reported using sanitary pads during the recent menses respectively. ${ }^{5,8}$ The recent improvement in commercially available absorbent accessibility could be a reason for the difference. Mothers are the leading source of information about menses. There were gaps in information among females on how to manage their menses safely. Some of the high school females do not know the origin of menses blood. Many of the 
Table 5 Multiple Logistic Regression Analysis on Data Collected from High School Females in Ambo City, West Shoa Zone, Oromia Regional State, Ethiopia, 2018

\begin{tabular}{|c|c|c|c|c|c|}
\hline \multirow[t]{2}{*}{ Variables } & \multicolumn{2}{|c|}{ MHM Practice } & \multirow[t]{2}{*}{ COR with $95 \% \mathrm{Cl}$} & \multirow[t]{2}{*}{ AOR with $95 \% \mathrm{Cl}$} & \multirow[t]{2}{*}{ p-values } \\
\hline & Unsafe & Safe & & & \\
\hline \multicolumn{6}{|l|}{ Age } \\
\hline $12-17$ & 160 & 152 & $0.21 I(0.07,0.63)$ & $0.16(0.045,0.57)$ & 0.005 \\
\hline$\geq 18$ & 20 & 4 & Ref & & \\
\hline \multicolumn{6}{|l|}{ Residence } \\
\hline Urban & 169 & 143 & $1.39(0.61,3.21)$ & $2.37(0.80,7.06)$ & 0.12 \\
\hline Rural & 11 & 13 & Ref & & \\
\hline \multicolumn{6}{|l|}{ Religion } \\
\hline Orthodox & 72 & 86 & $0.47(0.22,1.00)$ & & 0.56 \\
\hline Protestant & 85 & 57 & $0.84(0.39,1.80)$ & & 1.001 \\
\hline Others* & 23 & 13 & Ref & & \\
\hline \multicolumn{6}{|l|}{ Fathers educational status } \\
\hline Illiterate & 22 & 37 & Ref & & \\
\hline Grade I-6 & 38 & 20 & $3.2(1.5,6.8)$ & $0.46(0.15,1.33)$ & 0.15 \\
\hline Grade 7-12 & 69 & 42 & $2.76(1.44,5.30)$ & $0.28(0.10,0.78)$ & 0.02 \\
\hline Degree and above & 52 & 56 & $1.5(0.8,2.93)$ & $0.28(0.10,0.88)$ & 0.03 \\
\hline \multicolumn{6}{|l|}{ Mothers educational status } \\
\hline Illiterate & 31 & 35 & Ref & & \\
\hline Grade I-6 & 60 & 43 & $1.58(0.85,2.94)$ & $0.8(0.31,2.08)$ & 0.65 \\
\hline Grade 7-12 & 54 & 29 & $2.10(1.1,4.07)$ & $1.56(0.50,4.85)$ & 0.44 \\
\hline Degree and above & 34 & 47 & $0.81(0.42,1.57)$ & $0.36(0.11,1.18)$ & 0.09 \\
\hline \multicolumn{6}{|l|}{ Source of information about menses } \\
\hline Mother & 68 & 89 & $0.28(0.44,1.27)$ & $0.65(0.35,1.21)$ & 0.18 \\
\hline Teacher & 70 & 26 & $2.6(1.4,4.9)$ & $3.75(1.75,8.00)$ & 0.001 \\
\hline Others** & 42 & 41 & Ref & & \\
\hline \multicolumn{6}{|l|}{ History of sexual intercourse } \\
\hline Yes & 10 & 5 & $1.77(0.59,5.31)$ & I.I4(0.3I, 4.14) & 0.84 \\
\hline No & 170 & $15 \mid$ & Ref & & \\
\hline \multicolumn{6}{|l|}{ Get permanent pocket money for pad } \\
\hline Yes & 47 & 32 & $1.37(0.82,2.28)$ & $2.47(0.18,5.18)$ & 0.17 \\
\hline No & 133 & 124 & Ref & & \\
\hline \multicolumn{6}{|l|}{ Frequency of discussing menses } \\
\hline Frequently & 137 & 126 & $0.56(0.305,1.02)$ & $0.30(0.13,0.71)$ & 0.006 \\
\hline Sometimes & 4 & 11 & $0.19(0.052,0.67)$ & $0.1 \mathrm{I}(0.02,0.53)$ & 0.006 \\
\hline Almost Never & 37 & 19 & Ref & & \\
\hline
\end{tabular}

Notes: *Wakefata and Muslims. **Media, friends, other family members.

school females do not believe that the information they are accessing from different sources is enough in enabling them to practice safe MHM.

The school compounds were generally not friendly to the female students to manage their menses safely. Even though there were latrines separately for both males and females, they lack water, doors, and even dirty and not comfortable to use. These facts were confirmed by the researchers during school observation. Some of the school toilets lacked doors that were not clean and all of them had no water source.

As revealed during FGD, discussants reported that many female students do not come to school during their menses in fear of sudden blood leakage. This was evidenced by the fact that about $35 \%$ of the school female did not have access to sanitary pads during their recent menses. 
More than $32 \%$ of the females used homemade alternative sanitary materials for managing their menses. The homemade alternative material reaches from old clothes/ rags to clean new clothes. These old clothes may put the women at risk for infection and allergic reactions for their skin around the genitals. This finding is similar to the study conducted in Udaypur, Nepal. ${ }^{21}$

Compared with those aged greater or equal to 18 years, females younger than 18 years were $84 \%$ less likely to be their MHM practice was unsafe. Females whose fathers were illiterate were 3.57 times more likely to manage their menses unsafely. Compared with those females who never discussed menses with their mother, females who frequently discussed were $70 \%$ less likely to manage their MHM unsafely.

In conclusion, more than half of the high school females in the study area lack safe MHM, and the safe menses management practice was varied by the female age, frequency of discussing with mother, fathers' level of education, and source of information about menses. Almost all the schools were not female friendly for managing their menstrual hygiene. Female students require detail information/awareness about menses, MHM, and affordable sanitary materials.

Maintaining the school toilets and equipping them with WASH needs urgent and sustainable solutions. School-age females need urgent information and skills related to menses. This can be achieved through continuous awareness creation by preparing and distributing pamphlets in local languages. Any programs working to improve the MHM should target the identified factors in their plan.

\section{Limitation of the Study}

The menstrual hygiene issue is something considered taboo in the community and too sensitive to discuss openly. This may contribute to social desirability bias. Therefore, the interpretation of this finding should consider them.

\section{Abbreviations}

AOR, Adjusted odd ration; CI, confidence interval; FGD, focus group discussion; MHM, menstrual hygiene management; SD, standard deviation; WASH, water, sanitation, and hygiene.

\section{Acknowledgments}

We would like to acknowledge Ambo University for covering the data collectors and supervisors per diem. Our thanks also go to our study participants, and data collectors for their collaboration. We would like to thank Professor Roger Watson for his unreserved support in language editing.

\section{Funding}

Ambo University has covered the costs of data collectors and supervisors per diem. The funded organization has no role in designing the study, data collection, or manuscript preparation.

\section{Disclosure}

The authors declare that they have no competing interests in this work.

\section{References}

1. UNICEF and Emory University. WASH in schools empowers girls' education proceedings of the menstrual hygiene management in schools virtual conference 2013 III UNICEF and centre for global safe water, Emory University. New York. 2013. Available from: www.unicef.org/wash/schools. Accessed April 15, 2019.

2. Lawan UM, Yusuf NW, Musa AB. Menstruation and menstrual hygiene amongst adolescent school girls in Kano, Northwestern Nigeria. Afr J Reprod Health. 2010;14:201-207.

3. Wall LL, Belay S, Bayray A, Salih S, Gabrehiwot M. A community-based study of menstrual beliefs in Tigray, Ethiopia. Int $J$ Gynaecol Obstet. 2016;135:310-313. doi:10.1016/J. IJGO.2016.05.015

4. House S, Mahon T, Cavill S. Menstrual hygiene matters: a resource for improving menstrual hygiene around the world. Reprod Health Matters. 2013;21:257-259. doi:10.2307/43288983

5. Tegegne TK, Sisay MM. Menstrual hygiene management and school absenteeism among female adolescent students in Northeast Ethiopia. BMC Public Health. 2014;14(1):1118. doi:10.1186/1471-2458-141118

6. Tegegn A, Yazachew M, Gelaw Y. Reproductive health knowledge and attitude among adolescents: a community-based study in Jimma Town, Southwest Ethiopia. Ethiop J Health Dev. 2008. Available from: $\quad$ https://www.ejhd.org/index.php/ejhd/article/view/508. Accessed April 28, 2019.

7. Upashe SP, Tekelab T, Mekonnen J. Assessment of knowledge and practice of menstrual hygiene among high school girls in Western Ethiopia. BMC Womens Health. 2015;15(1):84. doi:10.1186/s12905015-0245-7

8. Azage M, Ejigu T, Mulugeta Y. Menstrual hygiene management practices and associated factors among urban and rural adolescents in Bahir Dar city administration, NorthWest Ethiopia. Ethiop J Reprod Health. 2018;10. Available from: http://ejrh.org/index.php/ ejrh/article/view/207. Accessed April 13, 2019.

9. Davis J, Macintyre A, Odagiri M, et al. Menstrual hygiene management and school absenteeism among adolescent students in Indonesia: evidence from a cross-sectional school-based survey. Trop Med Int Heal. 2018;23(12):1350-1363. doi:10.1111/tmi.13159

10. Hennegan J, Dolan C, Wu M, Scott L, Montgomery P. Measuring the prevalence and impact of poor menstrual hygiene management: a quantitative survey of schoolgirls in rural Uganda. BMJ Open. 2016;6(12):e012596. doi:10.1136/bmjopen-2016-012596

11. Baisley K, Changalucha J, Weiss HA, et al. Bacterial vaginosis in female facility workers in north-western Tanzania: prevalence and risk factors. Sex Transm Infect. 2009;85(5):370-375. doi:10.1136/ sti.2008.035543 
12. Torondel B, Sinha S, Mohanty JR, et al. Association between unhygienic menstrual management practices and prevalence of lower reproductive tract infections: a hospital-based cross-sectional study in Odisha, India. BMC Infect Dis. 2018;18(1):473. doi:10.1186/ s12879-018-3384-2

13. Mason L, Nyothach E, Alexander K, et al. 'We keep it secret so no one should know' - a qualitative study to explore young schoolgirls attitudes and experiences with menstruation in Rural Western Kenya. PLoS One. 2013;8(11):e79132. doi:10.1371/journal.pone.0079132

14. Sommer M, Figueroa C, Kwauk C, Jones M, Fyles N. Attention to menstrual hygiene management in schools: an analysis of education policy documents in low- and middle-income countries. Int J Educ Dev. 2017;57:73-82. doi:10.1016/J.IJEDUDEV.2017.09.008

15. Bott S, Jejeebhoy S, Shah I, Puri C. Towards adulthood: exploring the sexual and reproductive health of adolescents in South Asia. 2003. Available from: https://apps.who.int/iris/bitstream/handle/ $10665 / 42781 / 9241562501$. pdf; j s es sionid= 0C1BC887BCFF72D3EA7BD9118798089E? sequence $=1$. Accessed April 28, 2019.

16. Kaur R, Kaur K, Kaur R. Menstrual hygiene, management, and waste disposal: practices and challenges faced by girls/women of developing countries. J Environ Public Health. 2018;2018:1-9. doi:10.1155/ 2018/1730964
17. Sommer M, Hirsch JS, Nathanson C, Parker RG. Comfortably, safely, and without shame: defining menstrual hygiene management as a public health issue. Am J Public Health. 2015;105(7):1302-1311. doi:10.2105/AJPH.2014.302525

18. Bethany C, Freeman M, Dooley T, et al. Tools for assessing menstrual hygiene management in schools. 2013. Available from: www. unicef.org/wash/schools. Accessed March 25, 2020.

19. Ketema GT. Practice of menstrual hygiene and associated factors among female mehalmeda high school students in Amhara Regional State, Ethiopia. Sci J Public Health. 2014;2:189. doi:10.11648/j. sjph.20140203.18

20. OM O, UA S, GG J, AJ T. Menstrual health: the unmet needs of adolescent girls in Sokoto, Nigeria. Sci Res Essays. 2012;7:410-418. doi: $10.5897 /$ sre 11.1842

21. Morrison J, Basnet M, Bhatta A, Khimbanjar S, Joshi D, Baral S. Menstrual hygiene management in Udaypur and Sindhuli districts of Nepal. 2016. Available from: www.wateraid.org/mhm. Accessed July $9,2019$.
Risk Management and Healthcare Policy

\section{Publish your work in this journal}

Risk Management and Healthcare Policy is an international, peerreviewed, open access journal focusing on all aspects of public health, policy, and preventative measures to promote good health and improve morbidity and mortality in the population. The journal welcomes submitted papers covering original research, basic science, clinical \& epidemiological studies, reviews and evaluations,

\section{Dovepress}

guidelines, expert opinion and commentary, case reports and extended reports. The manuscript management system is completely online and includes a very quick and fair peer-review system, which is all easy to use. Visit http://www.dovepress.com/testimonials.php to read real quotes from published authors. 